\title{
Experimental studies on drilling in cryogenic conditions the industrial plastic parts
}

\author{
Sandor Ravai-Nagy ${ }^{1, *}$, Mircea Lobonţiu ${ }^{1}$, Nicolae Medan ${ }^{1}$ and Ferenc Szigeti $^{2}$ \\ ${ }^{1}$ Technical University of Cluj-Napoca, North University Center Baia Mare, Dr. V. Babeş str., 62A, \\ 430083, Baia Mare, România \\ ${ }^{2}$ University of Nyíregyháza, Institute of Engineering and Agricultural Sciences, Sóstói út 31/B, 4400, \\ Hungary
}

\begin{abstract}
Starting from an identified industrial need, therefore to process plastics in certain accuracy classes with machining time as low as possible, we studies performed in the field of plastic processing in cryogenic conditions. To parameterize the cutting potential of the industrial plastics with low rigidity in cryogenic conditions, the tests where we made was an exploratory character. During the experiments, we followed the variation of feed forces and cutting torque as well as the machining precision. We noticed an improvement in chip remove capacity of the tool and increased machining accuracy, due to low temperatures used during the processing.
\end{abstract}

\section{Introduction}

Diversification of the polymers (industrial plastics) applied to a wide range of industry fields, creates a constant challenge in determining the optimal conditions for machining by chip removing.

The dimensional accuracy and surface quality, prescribed by designers, must be achieved after processing at a low cost.

Studying scientific literature relating to processing materials in cryogenic conditions, we identified three areas of research, characterized by:

- cooling of the cutting tool [1], [2];

- cooling of the work piece [3], [4], [5];

- cooling of the cutting tool and the work piece [6].

In the present paper, we present the results of exploratory experiments achieved in the field of processing by drilling certain industrial plastics, used in the car industry components in the framework of the car body manufacturing lines.

Industrial plastics being sensitive to temperature, will limit the intensity of cutting parameters due to thermal effect caused by the chip removing and friction between piece and tool respectively between tool and chip. Due to the interaction between the lubricating and cooling liquid and the polymers, it is recommended the dry cutting manufacturing method.

\footnotetext{
*Corresponding author: Ravai.Nagy.Sandor@cunbm.utcluj.ro
} 
The industrial plastic change the mechanical properties depending on temperature. This was the reason we carried out the research in terms of cooling the work piece.

Thus, it was solved the cooling in cutting process and also the changing the mechanism of chip removal.

In the study, we follow the works piece cooling effects on the feed force, on the cutting torque and on the machining precision in the drilling process.

\section{Research layout}

The technological assembly used to perform the experiments shown in Figure 1, and consists of:

- Universal drilling machine $\mathrm{P}=3.2 \mathrm{~kW}, \mathrm{n}_{\max }=1400 \mathrm{rmp}, \mathrm{s}_{\max }=1.72 \mathrm{~mm} / \mathrm{rev}$;

- Clamping device for works piece, equipped with force and torque measuring sensor Kistler 9345B;

- Thermometer with $\mathrm{K}$ Type probe, measuring range $-200{ }^{\circ} \mathrm{C}$ to $1200{ }^{\circ} \mathrm{C}, 0,1{ }^{\circ} \mathrm{C}$ accuracy.

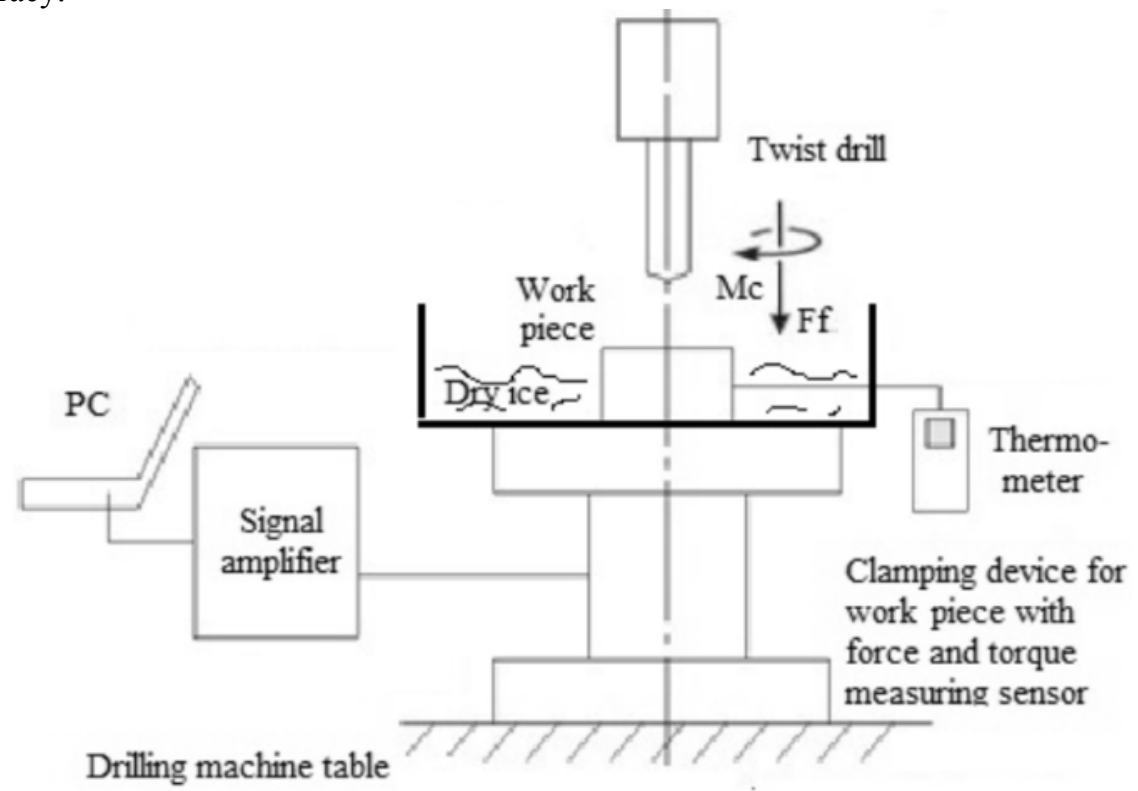

Fig. 1. Technological assembly used to perform the experiments

\section{Approach of the experiment}

In the experiment were performed holes using HSS twist drills, $\varnothing 12 \mathrm{~mm}$ diameter, in concordance with DIN 338.

Materials used in the experiment: SIKA Block M960, PA6oil, PA6SA

Feed: $0.32 \mathrm{~mm} / \mathrm{rev} ; 0.62 \mathrm{~mm} / \mathrm{rev}$

Spindle speed: $180 \mathrm{rpm}$ (Cutting speed: $6,5 \mathrm{~m} / \mathrm{min}$ );

Work piece temperature: $20^{\circ} \mathrm{C},-30{ }^{\circ} \mathrm{C}$

The coolant: dry ice, solid carbon dioxide.

Data that will result from the experiment:

- Feed force $\mathrm{F}_{\mathrm{f}}(\mathrm{N})$;

- Cutting torque $\mathrm{M}_{\mathrm{c}}(\mathrm{Nm})$; 
- Out of Roundness for the machined holes (mm).

Based on experimental data we track:

- The influence of temperature on the feed force and cutting torque;

- The influence of temperature on removed chip form;

- The influence of temperature on machined surface precision.

\section{Results}

\subsection{The influence of temperature on the feed force and cutting torque}

The variation of registered feed force " $\mathrm{F}_{\mathrm{f}}$ " and cutting torque $" \mathrm{M}_{\mathrm{c}}$ " for each material are presented in Figures 2, 3, 4 and 5.

In the Table 1 we present, as a synthesis, the average of the feed force and cutting torque depending on temperature. The feed and cutting speed (spindle speed) was constant under the experiment.
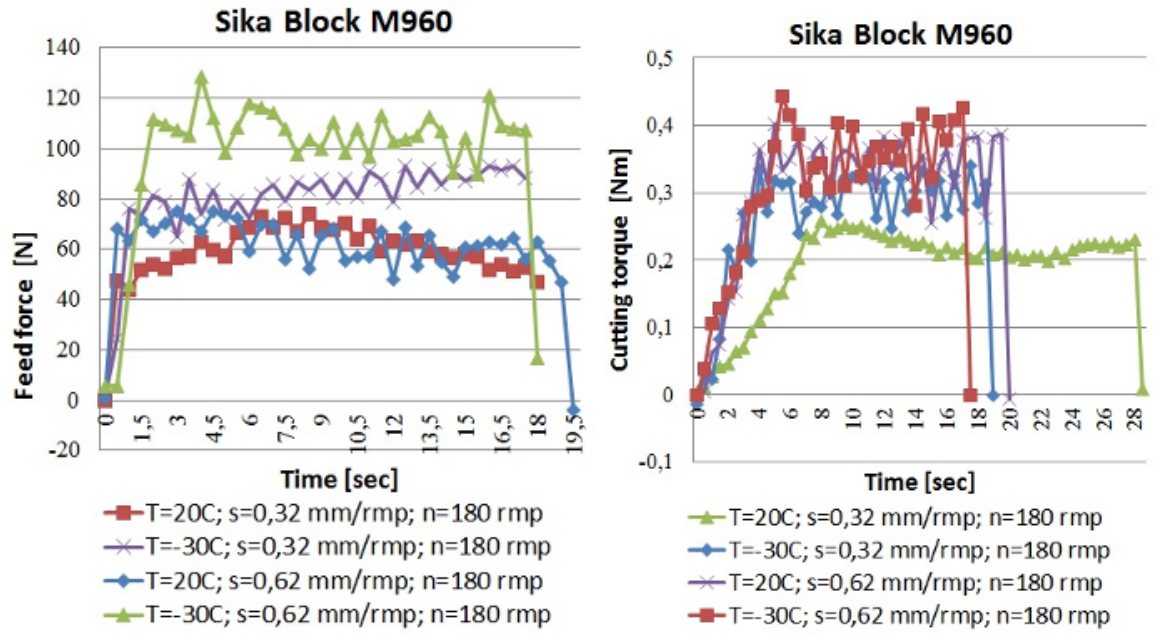

Fig. 2. The variation of feedd force and cutting torque for M960 material.
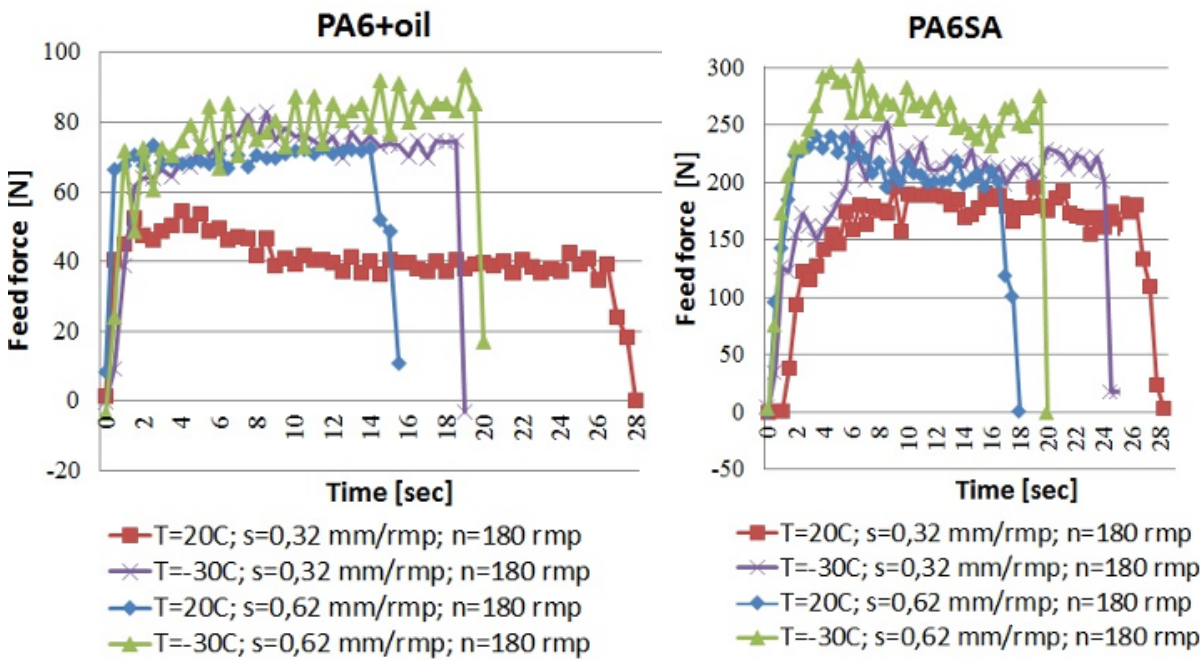

Fig. 3. The variation of feed force for PA6oil and PA6SA material. 

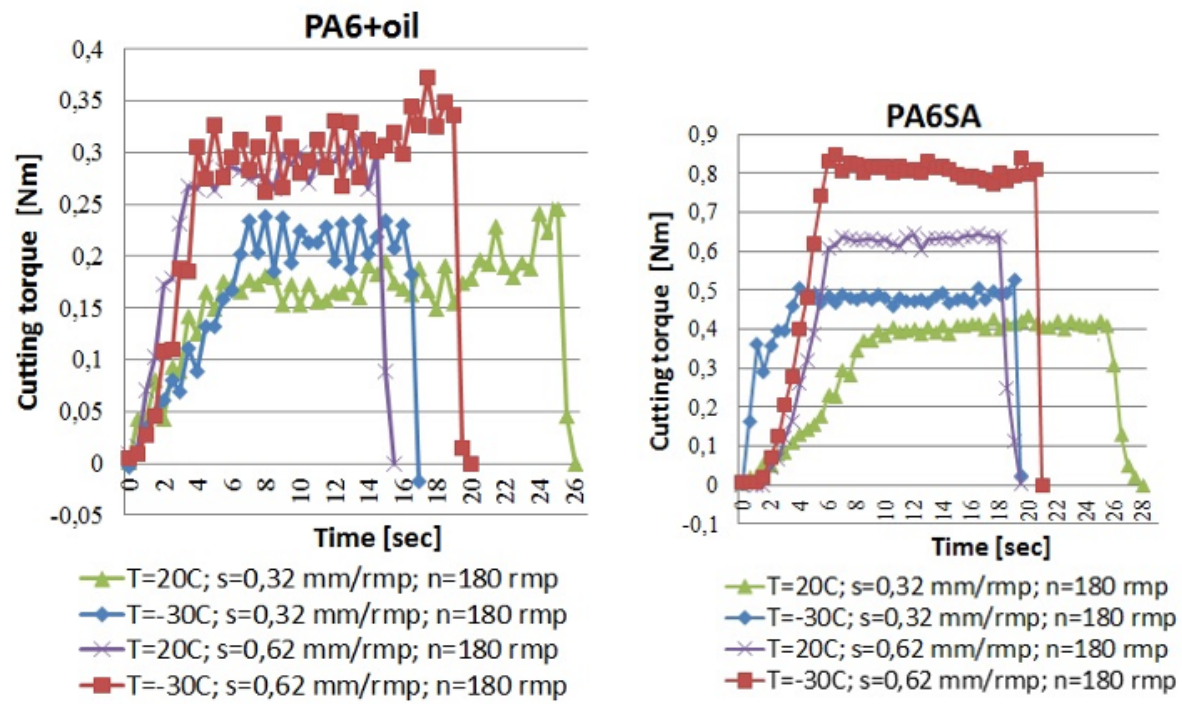

Fig. 4. The variation of cutting torque for PA6oil and PA6SA material.

Table 1. Experimental results. Average values of feed force $F_{f}$ and cutting torque $M_{c}$

\begin{tabular}{|c|c|c|c|c|c|c|c|c|c|}
\hline & \multicolumn{3}{|c|}{ Sika Block M960 } & \multicolumn{2}{|c|}{ PA6 oil } & \multicolumn{3}{|c|}{ PA6SA } \\
\hline & & \multicolumn{2}{|c|}{$\mathrm{n}=180[\mathrm{rmp}]$} & \multicolumn{2}{|c|}{$\mathrm{n}=500[\mathrm{rmp}]$} & \multicolumn{2}{|c|}{$\mathrm{n}=180[\mathrm{rmp}]$} & \multicolumn{2}{|c|}{$\mathrm{n}=180[\mathrm{rmp}]$} \\
\hline & & $\begin{array}{c}\mathrm{s}=0.32 \\
{[\mathrm{~mm} /} \\
\mathrm{rev}]\end{array}$ & $\begin{array}{c}\mathrm{s}=0.62 \\
{[\mathrm{~mm} /} \\
\mathrm{rev}]\end{array}$ & $\begin{array}{c}\mathrm{s}=0.32 \\
{[\mathrm{~mm} /} \\
\mathrm{rev}]\end{array}$ & $\begin{array}{c}\mathrm{s}=0.62 \\
{[\mathrm{~mm} /} \\
\mathrm{rev}]\end{array}$ & $\begin{array}{c}\mathrm{s}=0.32 \\
{[\mathrm{~mm} /} \\
\mathrm{rev}]\end{array}$ & $\begin{array}{c}\mathrm{s}=0.62 \\
{[\mathrm{~mm} /} \\
\mathrm{rev}]\end{array}$ & $\begin{array}{c}\mathrm{s}=0.32 \\
{[\mathrm{~mm} /} \\
\mathrm{rev}]\end{array}$ & $\begin{array}{c}\mathrm{s}=0.62 \\
{[\mathrm{~mm} /} \\
\mathrm{rev}]\end{array}$ \\
\hline \multirow{2}{*}{$\begin{array}{l}\text { Feed } \\
\text { force, } \\
\mathrm{F}_{\mathrm{f}}[\mathrm{N}]\end{array}$} & $20^{\circ} \mathrm{C}$ & 59.49 & 63.33 & 65.92 & 75.99 & 41.30 & 70.99 & 177.1 & 214.8 \\
\hline & $-30^{\circ} \mathrm{C}$ & 84.36 & 107.1 & 80.40 & 113.2 & 74.94 & 82.47 & 216.4 & 263.1 \\
\hline \multirow{2}{*}{$\begin{array}{l}\text { Cutting } \\
\text { torque, } \\
\mathrm{M}_{\mathrm{c}}[\mathrm{Nm}]\end{array}$} & $20^{\circ} \mathrm{C}$ & 0.222 & 0.346 & 0.237 & 0.344 & 0.191 & 0.286 & 0.411 & 0.629 \\
\hline & $-30^{\circ} \mathrm{C}$ & 0.299 & 0.365 & 0.283 & 0.367 & 0.216 & 0.307 & 0.484 & 0.801 \\
\hline
\end{tabular}

\subsection{The influence of temperature on the shape of detached chips}

In the case of M960 materials the chips become smaller with decreasing the temperature and drill ejects easily from hole, Figure 5.
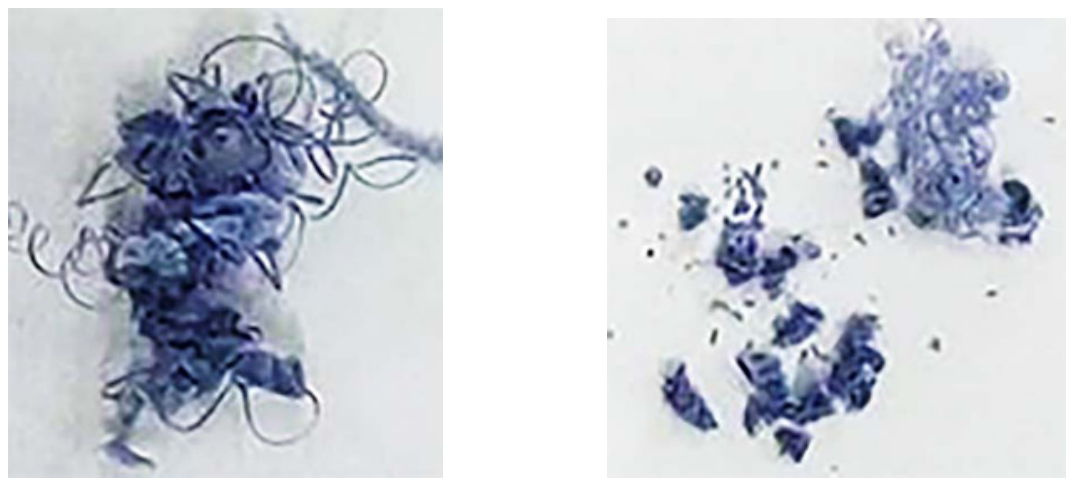

Fig. 5. The shape of the chip at $20{ }^{\circ} \mathrm{C}$ respectively at $-30{ }^{\circ} \mathrm{C}$ for M960 material (feed $0.62 \mathrm{~mm} / \mathrm{rev}$ ). 

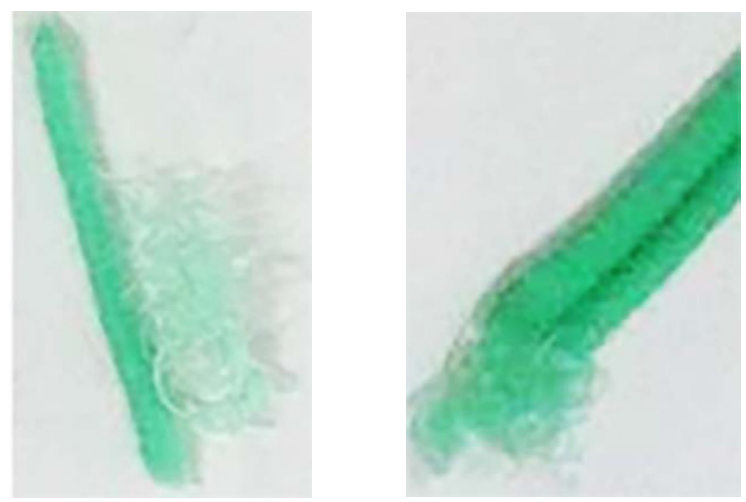

Fig. 6. The shape of the chip at $20{ }^{\circ} \mathrm{C}$ respectively at $-30{ }^{\circ} \mathrm{C}$ for PA6oil material (feed $0,62 \mathrm{~mm} / \mathrm{rev}$ )

With decreasing the temperature, the removed chips of PA6SA and PA6oil materials became more rigids and with larger volume. Contrary to the formed chip at $20{ }^{\circ} \mathrm{C}$ with a tendency of clogging of the drill at $-30^{\circ} \mathrm{C}$ it is easily discharged from the machined hole, Figure 6.

\subsection{The influence of temperature on machined surface precision}

A stage of the study was to verify the accuracy of drilled holes. Diameter holes were measured and in Table 2 were introduced the values of deviations.

Table 2. Deviations from the hole diameter

\begin{tabular}{|c|c|c|c|c|c|c|c|c|}
\hline & \multicolumn{3}{|c|}{ M960 } & \multicolumn{3}{c|}{ PA6AS } \\
\hline Temperature & \multicolumn{2}{|c|}{$20{ }^{\circ} \mathrm{C}$} & \multicolumn{2}{c|}{$-30{ }^{\circ} \mathrm{C}$} & \multicolumn{2}{c|}{$20{ }^{\circ} \mathrm{C}$} & \multicolumn{2}{c|}{$-30{ }^{\circ} \mathrm{C}$} \\
\hline $\begin{array}{c}\text { Feed } \\
{[\mathrm{mm} / \mathrm{rev}]}\end{array}$ & 0.32 & 0.62 & 0.32 & 0.62 & 0.32 & 0.62 & 0.32 & 0.62 \\
\hline Deviation & 0.03 & 0.03 & 0.02 & 0.01 & 0.02 & 0.02 & 0.01 & 0.01 \\
\hline
\end{tabular}

It can be observed that deviations from circularity of the hole are lower in case of machining at low temperatures.

\section{Conclusions}

Analysing the results of the experiments have found the following:

- At temperatures of $-30{ }^{\circ} \mathrm{C}$ increases the cutting forces (feed force) values;

- At temperatures of $-30{ }^{\circ} \mathrm{C}$ increases the cutting torque values;

- The chips are more rigid at temperatures $-30{ }^{\circ} \mathrm{C}$ and it evacuated more easily from the drilled hole and not remain locked in the drill channel; 
- The holes machined at $-30{ }^{\circ} \mathrm{C}$ presents a $50 \%$ reduced deviation from circularity, which for certain conditions in industrial manufacturing requires no boring;

- In summary, the behaviour of industrial plastics, when processing in cryogenic conditions by chip remove methods is different from the normal temperature.

Considering the results of exploratory research of the industrial plastics machining in low temperature conditions, we consider it appropriate development of this research for various cutting parameters, various plastics and various cooling temperatures.

\section{References}

1. A.A. Khan, M. I. Ahmed, Journal of Materials Processing Technology 196, 149-154 (2008)

2. F. Pušavec, J, Kopač, Journal of Mechanical Engineering 57/9, 637-647 (2011)

3. B. Aldwella, J. O’Mahonyb, G., E. O’Donnella, Procedia CIRP 33, 305-310 (2014)

4. F. Ambrosy, F. Zanger, V., Schulze, I.S., Jawahir, Procedia CIRP 13, 169-174 (2014)

5. B. E. Mocerneac, M. Lobontiu, Academic Journal of Manufacturing Engineering 7(1) 51-56 (2009)

6. Y. Kakinuma, S. Kidani, T. Aoyama, CIRP Annals - Manufacturing Technology, 61(1), 79-82 (2012) 